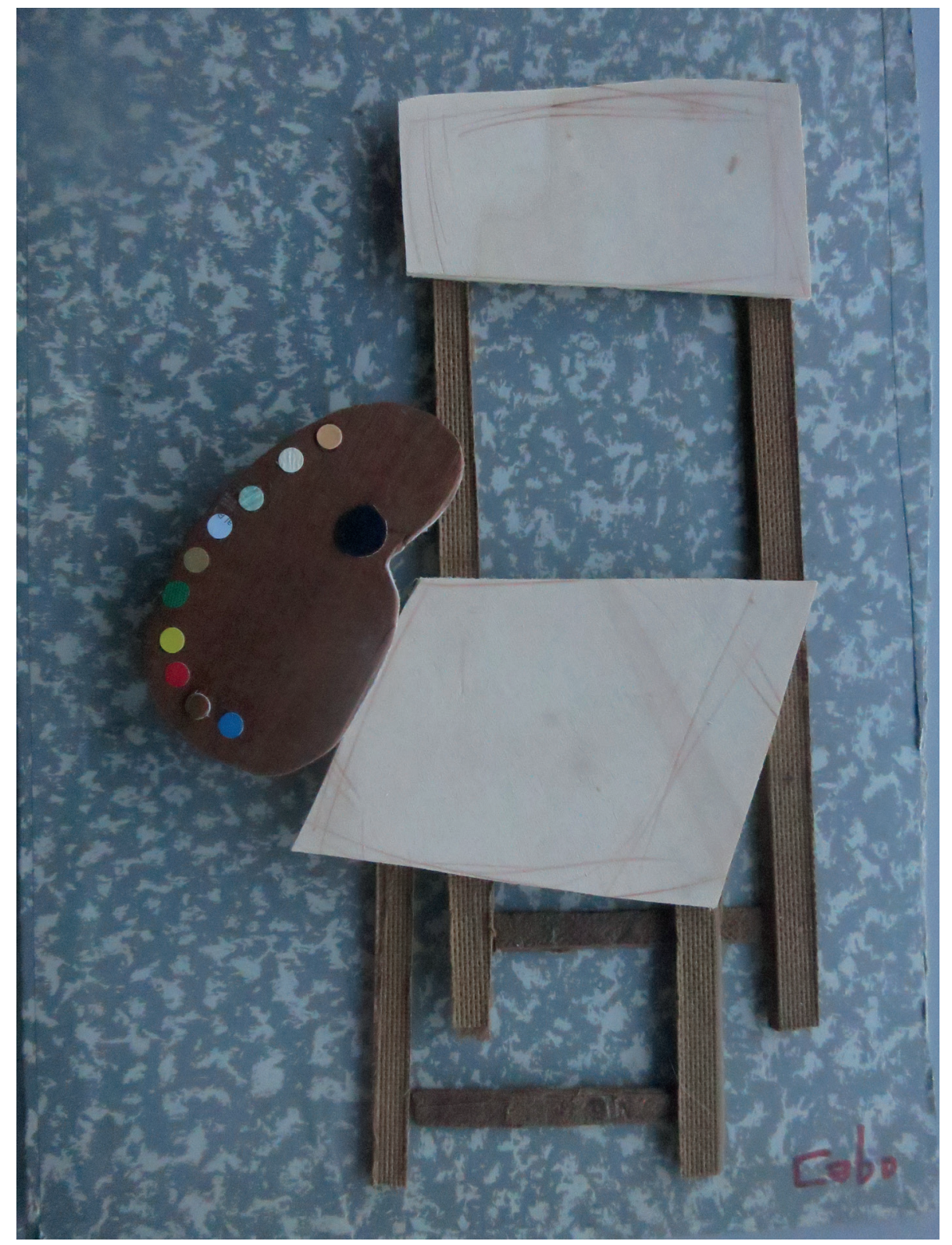


AUTOR: Javier Cabo 


\title{
Encontro con Daniel Asorey, autor de Nordeste
}

\author{
Soledad Ríos Santomé \\ [Recibido, 31 marzo 2019; aceptado, 13 xuño 2019] \\ http://dx.doi.org/10.15304/bgl.54.5933
}

Que tería sido de Galicia se o noso pasado fose outro? Que tería acontecido se tivesen triunfado os Irmandiños e os ideais da nosa sociedade fosen a xustiza, a igualdade e a prosperidade na nosa terra e alén dela? Cal tería sido esa outra (nosa) historia posible?

Daniel Asorey [Vidal] (Santiago de Compostela, 1970) busca contestar a estas preguntas no seu libro Nordeste (Editorial Galaxia, 2016), a súa estrea novelística.

O noso autor, mestre no ensino secundario, xa tiña publicado relatorios, artigos e recensións sobre lingua e literatura galegas, amais de material didáctico e libros de texto, alén de colaboracións en obras colectivas como De soños e memorias (2003) ou Muralla de Crescornio (1989).

Non lle foi mal a estrea ao noso autor. Premio de Narrativa Breve Repsol no 2016, finalista nos Premios da Crítica de Galicia e no San Clemente no 2017, Nordeste, completou unha nómina de premios cos que Daniel Asorey xa contaba no seu haber. Comezando nun afastado 1988 co I Certame de Relato Curto Cidade Vella, continuou co Premio de Narración Curta no I Certame Literario e de Investigación Terra de Melide (2001) e no ano seguinte (2002) co do Certame de Narracións Manuel Murguía (ex aequo). De xeito máis recente, acadou o Premio de Relato Breve Nélida Piñón con Anatema (2018) e foi finalista no Premio Xerais de Novela con As mulleres da fin do mundo (Xerais, 2019). A súa última obra, publicada neste mesmo ano, é Transmatria (Xerais, 2019), Premio Johán Carballeira de poesía 2018. 
Para esta primeira novela, Asorey escolle unha xeografía "que ama e que coñece ben" e convértea en espazo literario seguindo a estela de Graciliano Ramos ou Rachel de Queiroz. O nordeste brasileiro e Galicia son os territorios nos que viven (e morren) os seus personaxes, pero é outra Galicia, unha nacida dunha ucronía que ten como punto de partida a vitoria dos Irmandiños.

As protagonistas son tres mulleres pouco comúns: Carme de Candingas, vedora maior na República das Santas Irmandades de Galicia; Matilda, unha xornalista que traballa en São Paulo; e María Bonita, a máis famosa cangaçeira do Brasil. Sitúa as tres en dous eixos temporais diferentes: no primeiro cuarto do século XX (a grandes liñas) no caso do cangaço, e nun tempo máis impreciso, entre os séculos XVII e XVIII, para a República galega.

En Nordeste, Galicia ten colonias alén do mar, no Brasil, e a vedora maior ten o encargo de verificar que os ideais de xustiza, prosperidade e igualdade que inspiraron a República nacida das Revoltas Irmandiñas se cumpren nos territorios ultramarinos. Traerá novas deses territorios e deberá comunicarllos á Xunta Xeral á súa volta a Galicia, unha nación na que cre profundamente.

Matilda, xornalista e fotógrafa, valente e destemida, préstalles mirada e voz aos máis humildes e quere retratar de cerca o cangaço para o que se despraza até o nordeste, onde coñece a María Bonita coa que empatiza de inmediato. A cangaçeira é retratada entre os seus e no seu territorio, o sertão desértico e pobre, co que se sente fondamente identificada.

O escritor retrata tres mulleres libres, donas do seu destino, que rachan co agardado para elas no seu tempo. E que pagan o seu prezo.

Daniel Asorey ten reiterado que quixo darlle voz a quen non a ten. Por iso quixo proporcionárllela ás mulleres, esa metade (da poboación) silenciada; a Galicia, convertela nunha República e facela dona do seu destino "roubado hai 500 anos"; e ao nordeste brasileiro, "unha terra depauperada, esquecida" onde campou o cangaço, que non era outra cousa que "o berro dos desposuídos".

Pero, alén das mulleres, o noso autor introduce na súa historia outros elementos transversais que pairan en todo o texto: o capitalismo, o poder, o colonialismo, a escravitude... "O pobo sempre tivo que loitar para conseguir 
a liberdade", ten afirmado Daniel. "Nada está gañado. O capitalismo, o poder, asexan sempre".

A de Daniel Asorey é unha voz nítida e poderosa. Cun estilo directo, no que non escatima a dureza nas descricións ou na linguaxe e á vez dona dun gran lirismo que impregna todo o relato.

De capitalismo, de escravismo, de colonialismo... De todo isto fala Nordeste. Ah, e de feminismo, por suposto.

Sobre a súa obra isto é o que nos contou o seu autor.

SOLEDAD RÍOS SANTOMÉ. Vostede $x$ a ten editado outros libros, narracións breves, relato curto, poesía... con varios premios no seu haber. Non obstante, esta era a súa estrea como novelista. Cales eran as súas expectativas ao entregar o orixinal de Nordeste?

DANIEL ASOREY. As miñas expectativas non eran moi grandes. Aínda que escribo dende a adolescencia, e gañara daquela galardóns como a primeira edición do Caixa Galicia Biblioteca Club 33 ou fora premiado no Minerva ou no Cidade Vella e, posteriormente, no Manuel Murguía e no Terra de Melide, todo iso acontecera ao longo de moitos anos e sen apenas publicar. Ademais, eu nunca estou seguro do que fago, dubido, máis aínda ao escribir unha novela. Por iso, sinceramente, non tiña moitas perspectivas.

SRS. Sabemos que as críticas son maiormente boas, pero coñece vostede cal está a ser a acollida da novela?

DA. A crítica foi moi xenerosa coa novela. A acollida do público foi tamén unha sorpresa ben positiva e o libro segue a darme galanos inesperados, principalmente nos clubs de lectura, onde autor e lectoras podemos interaccionar. Con todo, quixera engadir que a situación do sistema literario galego é moi feble, por non dicir calamitosa, cunha administración que xoga á contra, xaora, temos que ser conscientes da realidade do sistema e ter os pés no chan, porque a nosa literatura conta moi pouco para unha sociedade que lle está dando as costas á súa lingua e á súa cultura.

SRS. Na actualidade xa foi traducida ao portugués e estase a ler no Brasil. Sabe como está a ser recibida? 
DA. Foi traducida, pero a distribución será nos próximos meses, coa idea da editorial de lanzala nun congreso que vai acontecer no Rio de Janeiro. A crítica chegou do ámbito académico brasileiro e foi moi positiva. Alí, persoas como Thayane Gaspar, pesquisadora da Universidade Estadual do Río de Janeiro ou o lingüista Marco Bagno, que acabou participando na tradución, foron auténticos entusiastas da obra, diría que case embaixadores da novela, motivo polo cal lles debo estar moi agradecido.

SRS. Vostede trata un dos grandes mitos dese país, o cangaço. Un tema tan delicado, tan imbricado no seu sistema cultural, non valorou que quizais se molestasen porque alguén alleo reinterpretase ese anaco de historia?

DA. É posible e seguramente terían razón. Porén, o feito de ter unha mirada afastada permíteme dicir certas cousas que para un nordestino talvez sexan máis difíciles, como pode ser falar da violencia do movemento. A mirada do outro quizais poida axudar. Alén diso, eu reinterpreto o cangaço dende unha novela na que aparece unha ucronía, polo que todo pode ser máis doado o achegamento que dende unha proposta de novela histórica convencional.

SRS. O cangaço, o nordeste brasileiro, o colonialismo, o escravismo... son xeografías e temáticas moi pouco babituais nas nosas letras. Teño escoitado que boubo un compoñente afectivo na súa escolla...

DA. Hai varios compoñentes afectivos co nordeste brasileiro. O nordeste é unha terra que visitei moitas veces e que coñezo bastante. Unha terra que amo. As súas xentes foron discriminadas e ridiculizadas por moitos gobernos federais. Do mesmo xeito, en cidades como São Paulo e Rio, en boa parte construídas por emigrantes nordestinos, existen moitos prexuízos contra o pobo nordestino. Para un galego é fácil de entender.

SRS. Eu quero reparar en como vostede comeza o libro. Na foto. Esa que está a tirar Matilda das cabezas dos cangaçeiros mortos expostas no Concello. É unba imaxe moi potente que nos introduce na historia, á vez que serve de marco e adianta parte do desenlace da novela. Coménteme o porqué desa apertura.

DA. Eu vin esa foto, que é unha imaxe icónica no Brasil, nunha exposición no Centro Cultural do Dragão do Mar de Fortaleza, no ano 2007, e quedei abraiado. Esa imaxe perseguiume, sabía que tiña que facer algo con ela, até 
que case sete anos máis tarde escribín a novela. Despois está tamén o feito de que é unha imaxe de autoría descoñecida, o que me deu pé a fabular acerca de quen puidera tirar aquela fotografía e converter a suposta fotógrafa nun personaxe da novela.

SRS. Vostede retrata aos cangaçeiros como valedores dunha terra esquecida, o nordeste, e dun pobo oprimido e sumido na miseria ("O cangaço era parte do nordeste incomprendido"). Non obstante, non escatima pasaxes de crueldade gratuita como o asasinato dos campesiños que fuxían da morte pola seca ou a violación grupal das criadas. É un retrato un tanto contraditorio, unha épica estragada pola crueldade.

DA. O cangaço é parte dunha terra dura, inhóspita e fermosa, o sertão nordestino, unha sabana cruel co ser humano máis humilde. Alén diso, o cangaço non é un movemento de emancipación popular, senón o berro desa terra humillada e depauperada. E ese berro é contraditorio. Os cangaçeiros xorden como tropas paramilitares de certos facendeiros e evolúen a unha sorte de bandidos que se enfrontan co Estado Novo de Getúlio Vargas, mandatario que encara un novo tipo de poder por veces próximo ao fascismo. Ademais, moitos dos feitos que atribúo ao cangaço son reais e están documentados.

SRS. Con todo, é consciente de que a súa mirada é amable?

DA. Non o creo, non. Hai certos capítulos que penso que non teñen para nada unha mirada amable co cangaço.

SRS. Alén do cangaço, existe unba reivindicación do nordeste brasileiro ("deserto bumilde e pobre") e das súas xentes ("Esta cidade estase construindo coas mans e os lombos do nordeste. No nordeste naceran os poboadores máis bumildes desta cidade, os traballadores con peor salario e condición”). Quixo darlle voz a este pobo...

DA. Si. Sempre. É unha teima darlle voz a quen no a ten. E nesa falta de voz está, evidentemente e como xa expliquei, o pobo nordestino. Até a chegada de Lula ao poder, nordestino el tamén, a situación dese territorio dentro do contexto do Brasil foi durísima, cunha emigración moi forte e todos os prexuízos que adoita xerar ese proceso. O fotógrafo Sebastião Salgado retratou imaxes aterrecedoras desa miseria.

SRS. Vostede dános conta dunha relación moi especial dos nordestinos co territorio no que habitan, coa súa terra. Describe unba relación na que a terra está personalizada 
(“fundirse coa terra cansa, aleitala..."), é parte da súa esencia... Hai como unha comuñón...

DA. Nordestinos ou non, eu creo que a maior parte dos seres humanos temos unha relación moi especial co territorio que habitamos e no que nacemos. Risco explicou iso no seu marabilloso "O sentimento da terra na raza galega", no no 1 da revista Nós. O que acontece é que o nordeste é unha terra agostada, onde cada pinga de auga conta e se valora. Esa terra seca é sumamente agradecida coa beizón da chuvia e florece espectacularmente cando cae un trebón ou unha arroiada.

SRS. E establece unba vinculación da terra coa morte e coa chuvia. Vostede escribe, por exemplo: "No sertão a morte sempre é vencida pola chuvia que retorna" ou "Virgulino dixéralle que era un tipo afortunado [...] para morrer un día como aquel. É bo, meu irmán, díxolle. A cousa máis bonita do mundo."

DA. A terra é vida, o lugar do que extraer a mantenza, porén, no nordeste a calor e o sol trouxeron moitas veces morte, estou pensando, por exemplo, na seca de 1915, que creou milleiros de desprazados e que foi respondida polo Goberno brasileiro coa creación de campos de concentración. Con esas reclusións tentaban evitar que os campesiños famentos entrasen na capital do Ceará, Fortaleza. Houbo milleiros de mortos, e esa situación inspirou obras como O quinze, de Rachel de Queiroz.

SRS. E a chuvia sempre está connotada positivamente...

DA. Os modelos imponos o poder, sabemos o que acontece co corpo feminino nun mundo controlado polo heteropatriarcado. Nós, as galegas e os galegos, estamos afeitos a cargar cunha imaxe colonizada de moitas cousas, mediatizada polo poder que vén da meseta, cunha climatoloxía propia. Digo isto porque resulta sorprendente ver informacións do tempo, supostamente a meteoroloxía debe ser unha ciencia obxectiva, onde se nos din cousas como que "mañá van ter bo tempo", falando de temperaturas de 40 graos ou explican que "en Galicia segue o mal tempo", referíndose a ceos anubrados ou a chuvascos acompañados de 20 graos de temperatura. Quen decide que iso é mal o bo tempo? En base a que un telexornal dá un dato subxectivo como algo obxectivo? Sinceramente, creo que estamos a falar de marcas de poder, tamén referidas á meteoroloxía. Se algo aprendín no nordeste brasileiro é 
que a chuvia é fermosa, é vida e un día anubrado será sempre lindo e belo. Habería que explicarllo aos telexornais españois.

SRS. De feito, a dúas das protagonistas (María Bonita -"non hai día mellor para morrer que un día de chuvia"- e Carme de Candingas - "As nubes (...) mollan delicadamente o rostro dela" -) regálalles a chuvia nos seus últimos momentos.

DA. Iso, repito, ten que ver coa imaxe da chuvia no sertão, un deserto que se converte nun mar de flores en poucas horas. $\mathrm{O}$ abrochar da vida no sertão é un dos espectáculos máis sorprendentes que xa vin. A semana santa pasada aconteceu isto diante de min, visitando Quixeramobim, en pleno sertão cearense. Por certo, nesa vila naceu Antônio Conselheiro, o personaxe histórico que inspirou a novela La guerra del fin del mundo, de Vargas Llosa.

SRS. A morte (as mortes) que vostede describe sempre son violentas, algunbas especialmente sanguinarias. Non obstante, están descritas dun xeito moi poético, dulcificado...

DA. Seguramente a descrición ten que ver co estilo que emprego, talvez un tanto lírico, o que ao mellor é un desacerto na narrativa, non o sei. No entanto, pode que tamén iso se deba a que eu teño un nivel de tolerancia moi baixo coa violencia, nin nos filmes nin na literatura, arrepíame o asañamento e o macabro. Así que non é raro que se teño que tratar a violencia non me recree nela.

SRS. Vostede toma como protagonista a tres mulleres, entre elas, María Bonita, a máis famosa cangaçeira, e imprímelle unha impronta rebelde, liberadora ("As mulleres enchen o cangaço dun berro liberador", "Elas morren e matan, ao tempo que arredan as súas figuras do esquema que a sociedade lles marcara en trazos grosos"). Para vostede é unha muller que quere mudar o mundo...

DA. María Bonita dende logo muda o seu propio mundo cando se bota ao cangaço e seguramente muda o doutras moitas mulleres ao ver como elas asumen papeis até o daquela prohibidos.

SRS. Eses trazos marcados pola sociedade dos que vostede fala apreciámolos, por exemplo, no legado de resignación da súa nai ("O mundo é dos homes, dixéralle"), e dos que ela busca liberarse pero acaban frustrándose ("Quizais non baxa un cami- 
no para elas nin sequera na apoteose do sertao", "A realidade da banda repetía os mesmos esquemas dos que ela andaba a fuxir desde pequena"). Non cre que nin nese ambiente a mudanza de roles fose posible?

DA. Nese ambiente hai unha notable mudanza de roles, pois cangaçeiros e cangaçeiras fan os mesmos labores: eles cosen e cargan auga e elas alampan tiros sen medo. Así e todo, sempre, tamén no cangaço, está presente a violencia masculina, esa violencia que converte as mulleres en campo de batalla.

SRS. As outras dúas protagonistas, Carme de Candingas, vedora maior da República das Santas Irmandades de Galicia, e Matilda, a fotógrafa que percorre o nordeste, son mulleres que deciden a súa posición no mundo, que rachan co papel que se agardaría dunha muller no seu tempo. Quizais teñen antecedentes reais...

DA. Carme de Candingas foi a miña avoa, unha muller forte e resistente que tivo que sufrir o franquismo e que viu como se evaporaban os soños que ela e outras moitas coma ela tiñan para as súas vidas. Dándolle o seu nome a un dos personaxes quixen render unha homenaxe ás mulleres que neste país sufriron a guerra e a posguerra, e a quen non só lles roubaron a liberdade, senón tamén o dereito a gozar da corporalidade. Por outra banda, Matilda é un personaxe inspirado en Ruth Matilda Anderson, esa fotógrafa norteamericana que na década dos vinte fai unha viaxe polo estado español e pola nosa terra, poñéndolle ollos ao país e ás súas xentes máis humildes. Ruth Matilda Anderson acaba citando a Rosalía de Castro nalgunha obra súa e expresa unha sensibilidade valente coas clases populares deste país, de aí o seu nome para o da xornalista da novela.

SRS. Pese a brillantez de ambas, non son quen de subtraerse ao fracaso dos seus obxectivos. Vostede describeas atrapadas por un momento bistórico que acaba por ser decisivo e os seus finais son tráxicos. Por que este aniquilamento?

DA. No caso de Matilda, Benjamin Abrahão, un dos fotógrafos dos que falo na novela, morre asasinado en circunstancias entrañas que poden estar relacionadas coa represión do Estado Novo. No caso do personaxe de Carme de Candingas, alguén cre que unha muller que desafía o capital vai sobrevivir?

SRS. E o recurso á bruxería é moi fácil e eficaz para desfacerse das mulleres... 
DA. A novela bebe de certas lecturas, por suposto. Unha desas lecturas que me axuda a tecer unha das teses da novela é a coñecidísima obra de Silvia Federici Caliban e a bruxa, onde se expón con rotundidade que o capitalismo medrou grazas ao sangue das mulleres, dos nativos americanos e dos escravos africanos. E iso defendo na novela.

SRS. Pero vostede quixo irmandar as tres mulleres no momento da súa morte... Quizais (e cito textual) por "un pacto tácito que só existe entre as mulleres, algo que abarca a memoria e a opresión"?

DA. Pode ser, non o sei, que as irmandase na morte, o que si teño claro é que a historia das mulleres, o auxe do feminismo, a forza das súas reivindicacións... bebe dun pacto tácito que abarca a memoria das que estiveron antes e da opresión vivida. É un magnífico exercicio de sororidade colectiva.

SRS. Quitado o descrédito aplicado á opinión da vedora, vostede fai mención de xeito moi explícito á violencia masculina contra as mulleres, ("Nunca máis hei tolerar que outra muller sexa declarada campo de batalla”, “...mulleres, seres aos que un bome pode domar, posuír, dobrar tan só co seu falo sagrado", "A violación sempre foi unha arma, a demostración máis práctica do poder e do dominio")

DA. A violencia contra as mulleres é a maior forma de violencia exercida contra calquera colectivo, porque abarca o $50 \%$ da poboación do mundo. Isto levou a un auténtico feminicidio, sen contar con outras formas de violencia machista máis sutís e moi perigosas.

SRS. E cunha linguaxe crúa, espida, sen demasiados enfeites...

DA. Non son consciente, pode ser. Como dixen, creo que a voz do narrador tende ao lirismo na linguaxe.

SRS. $O$ discurso de Carme de Candingas ao chegar emprega unha linguaxe inzada de grandes conceptos que é desmontada pola realidade coa que se atopa. É buscado este contraste?

DA. Carme de Candingas cre nesa nación na que habita, xurdida da Revolución Irmandiña, pero coido que cando ela toma a voz diante do Consello se amosa firme e directa, nada compracente e moi pouco idealista. 
SRS. Sitúa á vedora nunha ucronía que ten como punto de partida unhas Guerras Irmandiñas triunfantes ("os seus devanceiros botaran abaixo as fortalezas onde residía o mal e a corrupción”). A pesar diso e dos grandes principios proclamados, o resultado no difire do das outras nacións coloniais. Non cre que esa outra nación posible sería capaz de facelo - bistoricamente-mellor?

DA. É posible, pero eu non quero caer no maniqueísmo de soñar una nación nosa libre e perfecta, cousa que me gustaría, pois igual que imaxino mulleres libres soñarei matrias ou transmatrias libres. Velaquí que se invento una República Galega me atreva a denunciar nela tamén o poder, tanto económico como do heteropatriarcado.

SRS. En realidade, vostede retrata o triunfo dun capitalismo sen fisuras. Non importan as vidas, os principios, os gobernos... ("Endexamais imaxinara que os intereses privados dunha soa empresa apodrentarían o goberno, facéndolle esquecer o ben común", "O valor comercial acabara impoñéndose ao da vida humana"). O capital sempre lle vai gañar ao poder político?

14 DA. Estao facendo. Alguén o dubida? O capitalismo derruba gobernos, dá golpes de estado 2.0 e retira os poucos dereitos adquiridos en loitas custosas. Por certo, o capital adoita ser sempre un poder invisible. As ideas que circulan seica xorden espontaneamente nunha prensa supostamente libre ou nunhas redes sociais aparentemente sen censura.

SRS. Tampouco obvia que entre os recursos empregados para agrandar o capital está o escravismo, que se practica sen dó ("Os cantos e berros dos escravos son as ventosidades fétidas dun capitalismo que abrolla florecente”).

DA. Como dixen, Federici explícao moi ben no seu libro Caliban e a bruxa. A escravitude supuxo importantísimos gaños dentro do capitalismo comercial. Nacións como Holanda fixeron da escravitude un negocio moi rendible, talvez o máis rendible da Compañía das Indias Occidentais, menos coñecida que a das Indias Orientais. Temos que pensar que Holanda acababa de se liberar do poder español e acabou sometendo a outras xentes para manter certas empresas e o que estas supoñían para as súas elites. Por certo, que eu saiba nin en Holanda nin tampouco no estado español non hai ningún museo da escravitude. Si, porque semella que a escravitude nos é algo alleo, cando non é así. Por exemplo, talvez fose o debate da escravitude o que acabase 
conducindo á abdicación de Amadeo de Saboia, que quería abolila. Dentro do estado español, os últimos escravos serán liberados só por volta de 1886 en Cuba, serán 30.000 e reciben o nome de patrocinados.

SRS. E a colonización, da que se elabora un discurso tan aceptable como falso ("Levaban mandando alí desde que os galegos e os portugueses aniquilaran os indios no nome da civilización da fe ou do comercio", "En Brasil, nas escolas describían a colonización galega como modelo de tolerancia e eficacia. Esquecían todos o sangue e as matanzas...", "Mentiras dunha bistoria contada desde Europa"). Algo tan esquecido para nós denúnciao vostede de xeito explícito.

DA. Estes días houbo unha polémica porque López Obrador, presidente de México, demandou que os Reis de España pedisen perdón pola conquista e os crimes cometidos nela. A reacción da prensa española, de partidos nacionalistas españois e mesmo de membros do Goberno Central foi, ao meu entender, clarificadora. Non se asumen os crimes acontecidos nos procesos de colonización, como se os mortos que causa a bandeira propia fosen menos graves que os outros. Colocando esa República Galega como unha república con colonias, quixen denunciar o proceso de colonización e o que implica sempre. Mesmo que leve a bandeira de un.

SRS. Na que recupera as palabras indíxenas que nomean a súa realidade (ipé, potiguaras, xokó, caroás, pitaguarís, urubús, kambeba, tapeba...).

DA. Tiven a sorte de traballar catro cursos como investigador na área de lexicografía do ILG ás ordes de Antón Santamarina. Se algo conseguiu Santamarina, foi transmitirnos o amor e o respecto polo léxico. O portugués do Brasil levou por diante centos de linguas, que ecoan nos topónimos e en fermosas palabras coas que se designan plantas, froitos, pobos ou mesmo aloumiños. Para min foi un deber tentar traer ao galego eses termos e tentar que sigan vivos na nosa lingua, facelos nosos.

SRS. Non podemos dicir que vostede intente disimular as súas querencias. A súa é unha voz social e comprometida.

DA. Tento selo. Ter unha voz oída é un privilexio e, daquela, o que eu pretendín foi ceder a miña voz aos que non a tiveron durante tantos séculos. Xa que logo, tiña claro que as protagonistas debían ser mulleres, pero por iso 
tamén tentei amosar o que aconteceu cos pobos nativos americanos ou cos escravos. E por iso tamén inventei unha República das Santas Irmandades da Galiza, porque creo que a voz da miña terra é subalterna e sofre aínda hoxe un proceso de silenciamento.

SRS. E para rematarmos, ten viaxado nestes últimos tempos a Brasil?

DA. Na semana santa do 2018 estiven de novo no nordeste, atravesando o sertão e seguindo as pegadas da revolta de Antônio Conselheiro. Este ano teño concedida unha licenza de estudos na Universidade Estadual do Ceará.

SRS. Para o momento político actual, co triunfo de Bolsonaro, cre acaída a frase "Matilda confirma a capacidade infinita dos humildes para se deixar enganar polos máis viles"? Como ve as perspectivas de futuro do país?

DA. Bolsonaro exemplifica perfectamente esa frase, porén, tamén exemplifica que a extrema dereita está vivindo un rexurdir a nivel mundial, só temos que ollar o que acontece no estado español con Vox ou coa deriva de Pablo Casado e de Ciudadanos. Alén diso, Bolsonaro reflicte a complexidade do Brasil, un territorio onde a mentalidade escravista non abandonou aínda a boa parte da elite e mesmo da clase media.

SRS. Ten na rúa neste momento Transmatria, Premio Fohán Carballeira de Poesía. Leva unha racha importante de premios...

DA. Non son tantos, só son o Xoán Carballeira de poesía e o Nélida Piñón de narrativa.

SRS. E cales son os seus proxectos máis inmediatos?

DA. Ver a tradución de Nordeste ao brasileiro, e continuar coas presentación do poemario Transmatria e da nova novela As mulleres da fin do mundo.

SRS. Estas dúas obras semellan ter moito en común.

DA. Si, creo que son dous textos que basicamente tratan da necesidade de revolta contra un sistema que oprime corpos e dereitos. Nas dúas obras critícase que está acontecendo coa migración e coa política de fronteiras que 
converte os mares en tumbas. Tanto Transmatria como As mulleres da fin do mundo falan das identidades subalternas, mesmo na sexualidade, e reclaman a voz das mulleres para iniciar un mundo novo e máis xusto.

Soledad Ríos Santomé 